\title{
"On water" hydroformylation of 1-hexene using Rh/PAA (PAA = polyacrylic acid) as catalyst
}

\author{
W. Alsalahi and A. M. Trzeciak* \\ A new rhodium catalyst, Rh/PAA, obtained by the immobilization of $\mathrm{Rh}(\mathrm{acac})(\mathrm{CO})_{2}$ on polyacrylic acid (PAA), \\ was successfully applied for the hydroformylation of 1-hexene in a water medium. Spectroscopic analysis \\ evidenced that rhodium in Rh/PAA was chemically bonded to polyacrylic acid and formed a hydrido- \\ carbonyl rhodium compound in reaction with $\mathrm{H}_{2} / \mathrm{CO}$. Excellent results (98\% conversion, TOF 1000) were \\ obtained in the "on water" hydroformylation of 1-hexene when Rh/PAA was used together with a \\ hydrophobic phosphine (triphenylphosphine, tri-p-tolylphosphine, or diphenyl(2-methoxyphenyl) \\ phosphine). A similar efficiency was also obtained for a system composed of $\mathrm{Rh}(\mathrm{acac})(\mathrm{CO})_{2}$ and $\mathrm{PPh}_{3}$, \\ tested in the same conditions in water.
}

Received 19th April 2014

Accepted 30th June 2014

DOI: $10.1039 / c 4 r a 03568 b$

www.rsc.org/advances

\section{Introduction}

The hydroformylation reaction of olefins is a very important industrial process used for the production of aldehydes. ${ }^{1}$ This reaction was discovered in 1938 by Otto Roelen for a cobalt complex at Ruhrchemie in Germany. ${ }^{1}$ The aqueous-organic biphasic process for propene and butene hydroformylation was commercialized at Ruhrchemie-Rhone Poulenc in 1984. The main advantage offered by this process is the efficient separation of the catalyst from the organic products. This is possible because the catalyst bearing a water-soluble phosphine is kept in the aqueous phase, which is not miscible with the organic phase containing aldehydes. ${ }^{1}$

Water is the most plentiful, non-environmentally harmful, nontoxic, and nonflammable solvent used by nature for biological transformations, very attractive from an economical point of view. However, water also possesses the extraordinary ability to catalyze chemical transformations between some insoluble organic reactants. ${ }^{2-6}$ Moreover, unique reactivity and selectivity is observed in water when compared with conventional organic solvents. ${ }^{7-10}$ In 1980, Rideout and Breslow discovered rate acceleration of Diels-Alder reactions between nonpolar compounds in homogeneous aqueous solutions compared with the same reactions in organic solvents. ${ }^{\mathbf{1 1}}$ In 2005, Sharpless and his co-workers reported examples of organic syntheses performed in a water medium with reactants insoluble in water. ${ }^{9}$ Those reactions, termed "on water", gave higher yields and faster kinetics than in any organic solvent. An on-water reaction is the chemical process that takes place at the organic/water phase boundary (emulsion). The formation of hydrogen bonds in interfacial water molecules at the

Faculty of Chemistry, University of Wrocław, 14 F. Joliot-Curie St., 50-383 Wrocław, Poland.E-mail: anna.trzeciak@chem.uni.wroc.pl hydrophobic interface has a free dangling hydroxyl group that protrudes into the organic phase, plays a key role in catalyzing reactions, and demonstrates an extraordinary reaction rate acceleration. ${ }^{\mathbf{9}, 12}$ Such interactions were also studied in catalytic systems for hydroformylation. ${ }^{\mathbf{1 3 - 1 5}}$

In this paper, we report a new catalytic system for an onwater hydroformylation process by applying of a water-soluble immobilized catalyst, Rh/PAA, and a hydrophobic phosphine. The second system studied in the same conditions contained a water-insoluble complex, $\mathrm{Rh}(\mathrm{acac})(\mathrm{CO})_{2}$, as the rhodium source. These systems, applied for the first time in the hydroformylation of 1-hexene in water, gave very promising results. Until now there has been no detailed reports on the hydroformylation of higher olefins using the on-water methodology.

\section{Experimental}

\subsection{Materials}

The rhodium complex $\mathrm{Rh}(\mathrm{acac})(\mathrm{CO})_{2}$ was prepared according to the literature. ${ }^{\mathbf{1 6}}$

Polyacrylic acids $\left(M_{\mathrm{w}} \sim 1800\right.$ and 450000$)$ were purchased from Sigma-Aldrich; triphenylphosphine $\left(\mathrm{PPh}_{3}\right)$ was purchased from Avocado; 1-hexene was purchased from Merck; 1-octene was purchased from Sigma-Aldrich; hydrogen $\left(\mathrm{H}_{2}, 99.999 \%\right)$ and carbon monoxide (CO, 99.97\%) were procured from Air Products. All chemicals were used without any additional purification. Distilled water was used as the reaction medium.

\subsection{Synthesis of $\mathbf{R h} / \mathbf{P A A}\left(M_{\mathrm{w}} \sim 1800\right)^{17}$}

A solution of PAA $\left(M_{\mathrm{w}} \sim 1800,1.5 \mathrm{~g}\right)$ dissolved in water $(30 \mathrm{ml})$ was added to a suspension of $\mathrm{Rh}(\mathrm{acac})(\mathrm{CO})_{2}(1 \mathrm{~g})$ in water $(20 \mathrm{ml})$. After stirring for $24 \mathrm{~h}$ at room temperature, a second portion of PAA $(1.5 \mathrm{~g})$ in water $(20 \mathrm{ml})$ was added and stirring continued for the next $24 \mathrm{~h}$. During that time, the color of the 
mixture changed from green to black. Next, the mixture was filtered off, and the resulting filtrate was evaporated using a rotary evaporator yielding a black film of Rh/PAA containing $5.4 \%$ of Rh. A second synthesis, performed according to the same procedure but at the temperature of $35^{\circ} \mathrm{C}$, gave a product containing $10.2 \%$ of $\mathrm{Rh}$.

\subsection{Synthesis of Rh/PAA $\left(M_{\mathrm{w}} \sim 450000\right)$}

A solution of PAA $\left(M_{\mathrm{w}} \sim 450000\right)(1.5 \mathrm{~g})$ in water $(30 \mathrm{ml})$ was added to a suspension of $\mathrm{Rh}(\mathrm{acac})(\mathrm{CO})_{2}(1 \mathrm{~g})$ in water $(20 \mathrm{ml})$, and the mixture was stirred for $24 \mathrm{~h}$ at room temperature. The color changed from green to black. The mixture was filtered off, and the resulting filtrate was evaporated using a rotary evaporator yielding a black film of Rh/PAA containing $0.1 \%$ of $\mathrm{Rh}$.

\subsection{Synthesis of $\mathrm{HRh}(\mathrm{CO})\left(\mathrm{PPh}_{3}\right)_{3}$}

A mixture of $\mathrm{Rh}(\mathrm{acac})(\mathrm{CO})_{2}(0.00762 \mathrm{~g})$ and $\mathrm{PPh}_{3}(0.05136 \mathrm{~g})$ in water $(2 \mathrm{ml})$ was stirred under hydrogen gas $(1 \mathrm{bar})$ at $38^{\circ} \mathrm{C}$ for $c a .24 \mathrm{~h}$. The yellow precipitate was filtered off and dried.

${ }^{31} \mathrm{P} \mathrm{NMR}\left(\mathrm{C}_{6} \mathrm{D}_{6}\right): \delta 40.60 \mathrm{ppm}\left(\mathrm{d}, J_{\mathrm{Rh}-\mathrm{P}}=151.75 \mathrm{~Hz}\right)$. IR: $\nu_{\mathrm{Rh}-\mathrm{H}}$ $=2036 \mathrm{~cm}^{-1}, \nu_{\mathrm{CO}}=1921 \mathrm{~cm}^{-1}$.

\subsection{Preparation of samples for ICP measurements}

A $0.03 \mathrm{~g}$ sample of $\mathrm{Rh} / \mathrm{PAA}$ was placed in a $25 \mathrm{ml}$ volumetric flask, and $0.5 \mathrm{ml}$ of concentrated nitric acid and 1.5 of concentrated hydrochloric acid were added. The flask was filled to $25 \mathrm{ml}$ with distilled water, and the contents were mixed until complete dissolution.

\subsection{Characterization techniques}

The IR spectra of the samples were recorded in the range from 400 to $4000 \mathrm{~cm}^{-1}$ with a Bruker Vector 22 IR spectrometer. NMR spectra were recorded at room temperature on a Bruker Avance $500 \mathrm{MHz}$ spectrometer. Transition electron microscopy (TEM) was performed at $200 \mathrm{kV}$ using a FEI Tecnai $20 \mathrm{X}$-TWIN electron microscope. The Rh/PAA samples were dispersed in water and then suspended on a carbon grid. The Rh content in the Rh/PAA catalyst was determined using inductively coupled plasma atomic emission spectroscopy (ICP-AES) analysis (ARL Model 3410 , Fisons Instruments). The reaction products were identified and analyzed with a Hewlett-Packard 5890 II gas chromatograph equipped with an HP-5 column $(25 \mathrm{~m} \times 0.2 \mathrm{~mm})$ using helium as the carrier gas. Mass spectra were obtained using an HP 5971A mass selective detector.

\subsection{Hydroformylation of 1-hexene}

Hydroformylation experiments were carried out with 100, 50, and $35 \mathrm{ml}$ stainless steel autoclaves provided with manometers, thermostats, and magnetic stirrers. Weighted samples of $\mathrm{Rh} /$ PAA and $\mathrm{PPh}_{3}$ were placed in an autoclave under a nitrogen atmosphere, and the solvent (toluene, methanol, or water) and 1-hexene were introduced. The autoclave was closed, filled with hydrogen ( 5 bar) 3 times, and then pressurized with synthesis gas $\left(\mathrm{H}_{2}-\mathrm{CO}=1: 1\right)$ to $10 \mathrm{bar}$ and heated to $80^{\circ} \mathrm{C}$. After the reaction was finished, the autoclave was cooled to room temperature and depressurized. The organic products were separated by a vacuum transfer procedure and analyzed by means GC and GC-MS.

\subsection{Turnover frequency (TOF)}

The turnover number (TON) is defined as the number of moles of substrate that a mole of the catalyst can convert before becoming inactivated. The turnover frequency (TOF) is defined as the number of molecules reacting per active site in unit time. The TOF values were calculated as moles of the aldehyde [ $\mathrm{mol}$ of catalyst $]^{-1} t^{-1} ; t=$ time (h) was estimated from the linear part of the graph presenting pressure $v s$. time.

\section{Results and discussion}

\subsection{Characterization of Rh/PAA by IR}

The IR spectrum of $\mathrm{Rh}(\mathrm{acac})(\mathrm{CO})_{2}$ presented two peaks of carbonyl stretching frequencies $(\nu(\mathrm{CO}))$ at 2006 and $2064 \mathrm{~cm}^{-1}$ and two peaks originating from a coordinated acac ligand at 1253 and $1559 \mathrm{~cm}^{-1}$. The IR spectrum of Rh/PAA showed only one $\nu(\mathrm{CO})$ peak at $2064 \mathrm{~cm}^{-1}$ and no peaks for acac, indicating its removal from the coordination sphere of rhodium during reaction with PAA. In order to recognize reactivity towards substrates of hydroformylation, a solid sample of Rh/PAA was treated with $\mathrm{H}_{2}$ (5 bar), $\mathrm{CO}$ (5 bar), and $\mathrm{H}_{2}+\mathrm{CO}(10 \mathrm{bar})$. The reaction with $\mathrm{H}_{2}$ was also performed in benzene. The IR spectra of $\mathrm{Rh} / \mathrm{PAA}$, measured after treatment with $\mathrm{H}_{2}$ or $\mathrm{CO}$, showed unchanged bands in the region of $c a .2000 \mathrm{~cm}^{-1}$. In contrast, the IR spectrum of $\mathrm{Rh} / \mathrm{PAA}$ after reaction with syngas $\left(\mathrm{H}_{2}-\mathrm{CO}\right.$, $1: 1$ ) showed two new bands at 2100 and $2000 \mathrm{~cm}^{-1}$, attributed to rhodium-hydride and carbonyl vibrations (Table 1). Moreover, the shifting of $\nu(\mathrm{CO})$ from 2064 to $2073 \mathrm{~cm}^{-1}$ was observed (Table 1).

The TEM analysis of Rh/PAA did not show any $\mathrm{Rh}(0)$ nanoparticles; however, nanoparticles appeared after reaction of $\mathrm{Rh} / \mathrm{PAA}$ with $\mathrm{H}_{2} / \mathrm{CO}$. Small, $c a .4 \mathrm{~nm}$, as well as aggregated $\mathrm{Rh}(0)$ nanoparticles were found in different places of the TEM grids (Fig. 1). A quite different result was obtained when Rh/PAA reacted with $\mathrm{H}_{2} / \mathrm{CO}$ in water. The size of $\mathrm{Rh}(0)$ nanoparticles was smaller, about $2 \mathrm{~nm}$.

\subsection{Hydroformylation of 1-hexene}

The hydroformylation of 1-hexene was investigated in different solvents with $\mathrm{Rh} / \mathrm{PAA}$ as the catalyst and a 13-fold excess of a water-insoluble phosphine $\left(\mathrm{PPh}_{3}\right)$. Aldehydes were formed as the main reaction products, namely a linear aldehyde (1-heptanal) and a branched aldehyde (2-methyl-hexanal) (Scheme 1). Small amounts of the isomerization product, 2-hexene (1-4\%), were also found. In some experiments, performed in methanol, traces of an acetalization product, 1,1-dimethoxy-heptane, were identified.

In reactions performed without a solvent, in neat 1-hexene, only traces of aldehydes were formed. Similarly, a very low conversion of 1-hexene was noted in toluene, although $\mathrm{PPh}_{3}$ and 1-hexene are soluble in that solvent. Much better results were obtained in methanol and in a methanol-water mixture. In 
Table 1 IR data (in $\mathrm{cm}^{-1}$ ) of the Rh/PAA after reactions with $\mathrm{H}_{2}, \mathrm{CO}$ and $\mathrm{H}_{2}+\mathrm{CO}$

\begin{tabular}{|c|c|c|c|c|c|c|}
\hline \multirow{2}{*}{$\frac{\text { Sample }}{\operatorname{Rh}(\text { acac })(\mathrm{CO})_{2}}$} & \multirow{2}{*}{$\frac{\nu_{\mathrm{CO}}}{2006 \mathrm{vs}, 2064 \mathrm{vs}}$} & \multirow[t]{2}{*}{$\nu_{\mathrm{CO}}$ or $\nu_{\mathrm{Rh}-\mathrm{H}}$} & \multicolumn{4}{|c|}{$\nu_{\mathrm{CO}}(\mathrm{acac}), \nu_{\mathrm{CO}}(\mathrm{PAA}), \nu_{\mathrm{CH}}(\mathrm{PAA})$} \\
\hline & & & $1526 \mathrm{vs}$ & & & \\
\hline PAA & & & $1714 \mathrm{vs}$ & 1454w & $1415 w$ & $1269 \mathrm{~m}, 1165 \mathrm{~m}$ \\
\hline $\mathrm{Rh} / \mathrm{PAA}+\mathrm{H}_{2}$ & $2064 w$ & & $1714 v s$ & $1455 \mathrm{w}$ & $1415 w$ & $1272 \mathrm{~m}, 1177 \mathrm{~m}$ \\
\hline $\mathrm{Rh} / \mathrm{PAA}+\mathrm{CO}$ & $2065 w$ & & $1718 \mathrm{~s}$ & $1457 \mathrm{w}$ & $1405 w$ & $1263 \mathrm{~m}, 1172 \mathrm{~m}$ \\
\hline $\mathrm{Rh} / \mathrm{PAA}+\mathrm{H}_{2}+\mathrm{CO}(4 \mathrm{~h})$ & $2069 w$ & $2000 \mathrm{vw}, 2100 \mathrm{vw}$ & $1718 \mathrm{~s}$ & $1453 w$ & $1413 w$ & $1262 \mathrm{~m}, 1176 \mathrm{~m}$ \\
\hline $\mathrm{Rh} / \mathrm{PAA}+\mathrm{H}_{2}+$ benzene & $2070 w$ & & $1711 v s$ & $1457 w$ & $1415 \mathrm{w}$ & $1262 \mathrm{~m}, 1172 \mathrm{~m}$ \\
\hline
\end{tabular}

(a)
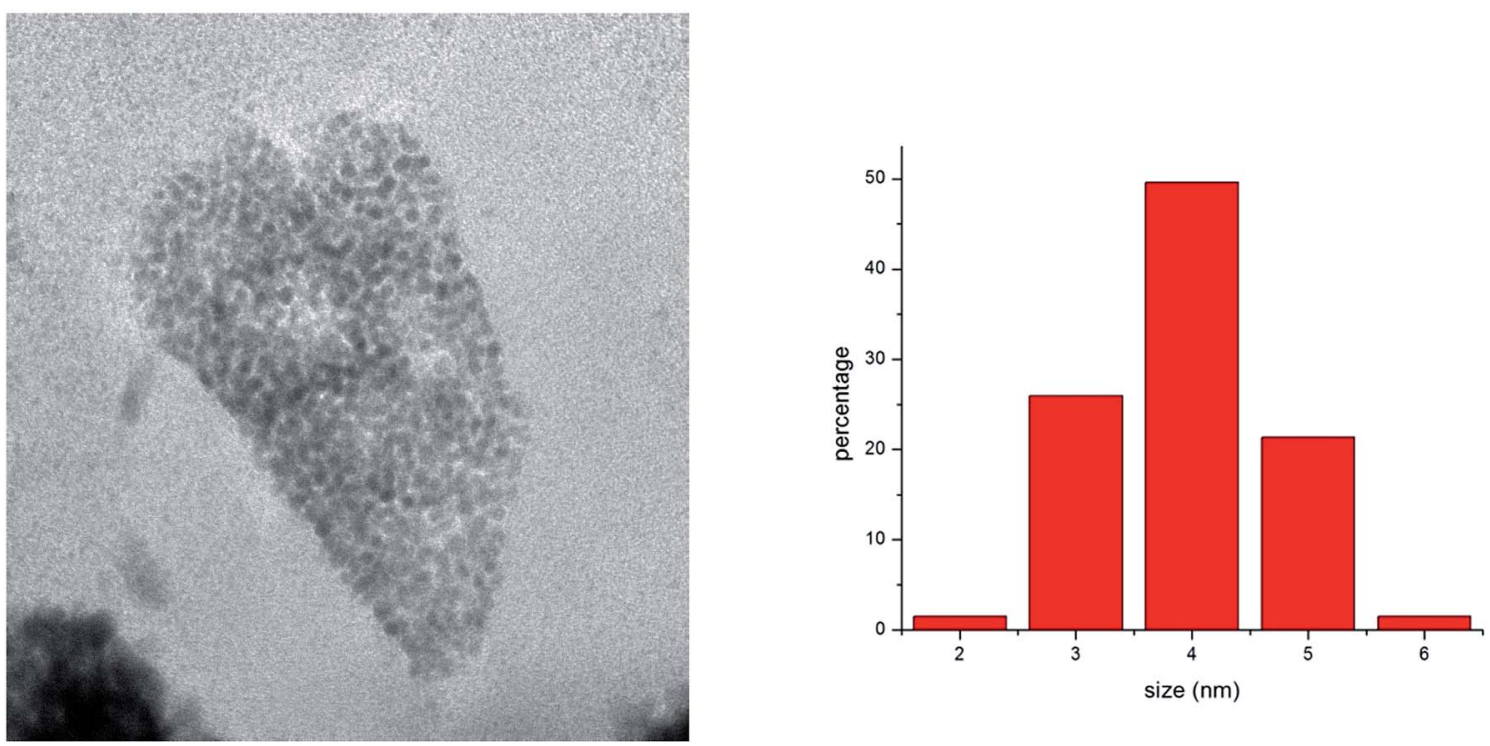

(b)
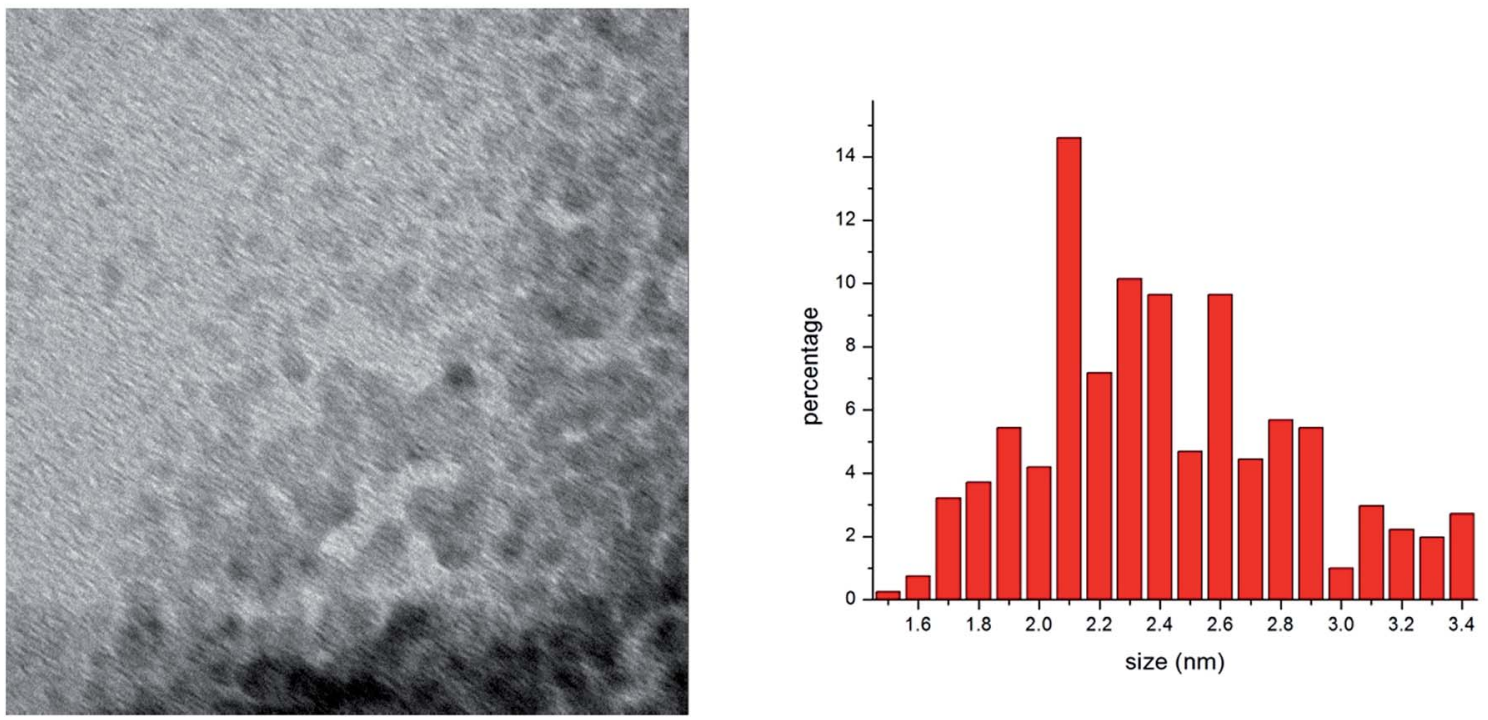

Fig. 1 Morphology and rhodium nanoparticle size after reaction of Rh/PAA with: (a) syngas $\left(\mathrm{H}_{2}-\mathrm{CO}\right), 10$ bar, $80{ }^{\circ} \mathrm{C}$ and (b) syngas $\left(\mathrm{H}_{2}-\mathrm{CO}\right), 10$ bar, $80^{\circ} \mathrm{C}$ in water. 


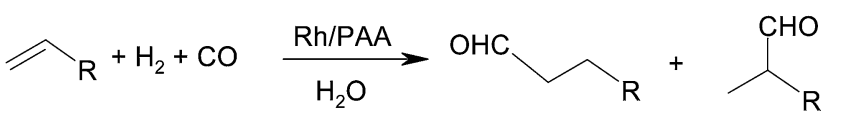

Scheme 1

particular, the $l / b$ ratio increased to a good value, 7.3. The addition of methanol to toluene resulted in a significant increase in 1-hexene conversion to aldehydes. Interestingly, when a toluene-water mixture was used, both conversion and selectivity were even better than for a toluene-methanol mixture. Such an effect was surprising because 1-hexene, $\mathrm{Rh} /$ PAA, and $\mathrm{PPh}_{3}$ are soluble in methanol and only Rh/PAA is soluble in water. As a rule, a faster reaction is expected in a homogeneous system than in a multiphase one. However, the most spectacular results, in respect to conversion, selectivity, and the reaction rate, were obtained in water only (Table 2). It is worth noting that the volume of water influences the reaction course only very slightly, and almost the same results were obtained using 0.5 or $1 \mathrm{ml}$ of water.

Consequently, further experiments were performed using water as the reaction medium. Such a procedure can be named "on water" because 1-hexene and $\mathrm{PPh}_{3}$ are insoluble in water. The effect of temperature on the hydroformylation of 1-hexene using the catalytic system $\mathrm{Rh} / \mathrm{PAA}+\mathrm{PPh}_{3}$ was studied at 50$90^{\circ} \mathrm{C}$ and a constant pressure of 10 bar (Table 3). An increase in 1-hexene conversion was observed with an increase in temperature. Thus, when temperature increased from 50 to $80{ }^{\circ} \mathrm{C}$, the yield of aldehydes increased from 21 to $94 \%$ with a decrease in the reaction time from $3 \mathrm{~h}$ to $1 \mathrm{~h}$ and a slight increase in the $l / b$ ratio from 4.3 to 6.9 . At $90{ }^{\circ} \mathrm{C}$, the yield of aldehydes decreases to $87 \%$, and $6 \%$ of 2 -hexene, an isomerization product, was formed. Consequently, aldehyde formation was preferred at $80^{\circ} \mathrm{C}$.

The effect of pressure on the catalytic activity of a Rh/PAA + $\mathrm{PPh}_{3}$ system was studied at $2-10$ bar and at $80{ }^{\circ} \mathrm{C}$, and the achieved results are shown in Table 3. When the pressure of the synthesis gas decreased from 10 to 2 bar, the conversion of 1hexene to the products decreased from 97 to $37 \%$ with a decrease in aldehyde yield from 94 to $31 \%$. However, lowering the synthesis gas pressure caused a remarkable increase in the $l / b$ ratio from 5.3 to 30 . This is in agreement with earlier observations that a good linearity of aldehydes is favored at low pressure. ${ }^{1}$ Lower pressure favors the formation of a linear alkyl rhodium species which is next transformed to a linear acyl intermediate and finally to a normal aldehyde.

As can be deduced from the data presented on Fig. 2, the effect of temperature on hydroformylation selectivity is rather small. For instance, the $l / b$ value changed from 4.3 to 6.9 when the temperature rose from 50 to $90^{\circ} \mathrm{C}$. In contrast, the pressure has a decisive effect on the yield of aldehydes as well as on hydroformylation selectivity. At 4 bar, the $l / b$ ratio was 22.2 , and at 2 bar, it reached 30 .

The effect of the $\left[\mathrm{PPh}_{3}\right] /[\mathrm{Rh}]$ ratio on the reaction course was studied in the range from 0 to 13 at $80{ }^{\circ} \mathrm{C}$ at $10 \mathrm{bar}$. The results presented in Table 4 show that in the absence of phosphine $\mathrm{Rh} /$ PAA catalyzes only the isomerization of 1-hexene to 2-hexene. However, already a 5-fold excess of $\mathrm{PPh}_{3}$ made it possible to get $57 \%$ of aldehydes. With an increase in the $\left[\mathrm{PPh}_{3}\right] /[\mathrm{Rh}]$ ratio, the conversion of 1-hexene increased to $92 \%$ together with an increase in the $l / b$ ratio to 5.7. Interestingly, high catalytic activity and good selectivity towards aldehydes were also obtained with the application of other water-insoluble phosphines, namely tri- $p$-tolylphosphine and diphenyl(2-methoxyphenyl) phosphine with Rh/PAA (Table 4). However, it should be noted that the kind of phosphine has a remarkable influence on the TOF values, and the highest TOF was obtained for $\mathrm{PPh}_{3}$.

The hydroformylation of 1-hexene was also performed with another Rh/PAA catalyst containing polyacrylic acid, $M_{\mathrm{w}}=$ 450000 . The rhodium content in this catalyst was significantly lower than in Rh/PAA immobilized on a polymer of $M_{\mathrm{w}}=1800$. Nevertheless, this catalysts also gave quite good results, $97 \%$ of aldehydes with $l / b=4.6$ after $150 \mathrm{~min}$.

In order to recognize the possibility of the in situ formation of an $\mathrm{Rh} / \mathrm{PAA}$ catalyst, $\mathrm{Rh}(\mathrm{acac})(\mathrm{CO})_{2}$ and $\mathrm{PPh}_{3}$ were used in the next experiment together with PAA added to the reaction mixture. The reaction was even faster than with Rh/PAA; however, a similar yield of the products was obtained. Next, $\mathrm{Rh}(\mathrm{acac})(\mathrm{CO})_{2}$ was used with $\mathrm{PPh}_{3}$ only, without PAA, and, surprisingly, the catalytic result was very promising (Table 5). The final composition of the products was similar to that obtained with Rh/PAA, but the TOF values were higher. At a

Table 2 Hydroformylation of 1-hexene catalyzed by Rh/PAA + PPh 3 in organic solvents and in water ${ }^{a}$

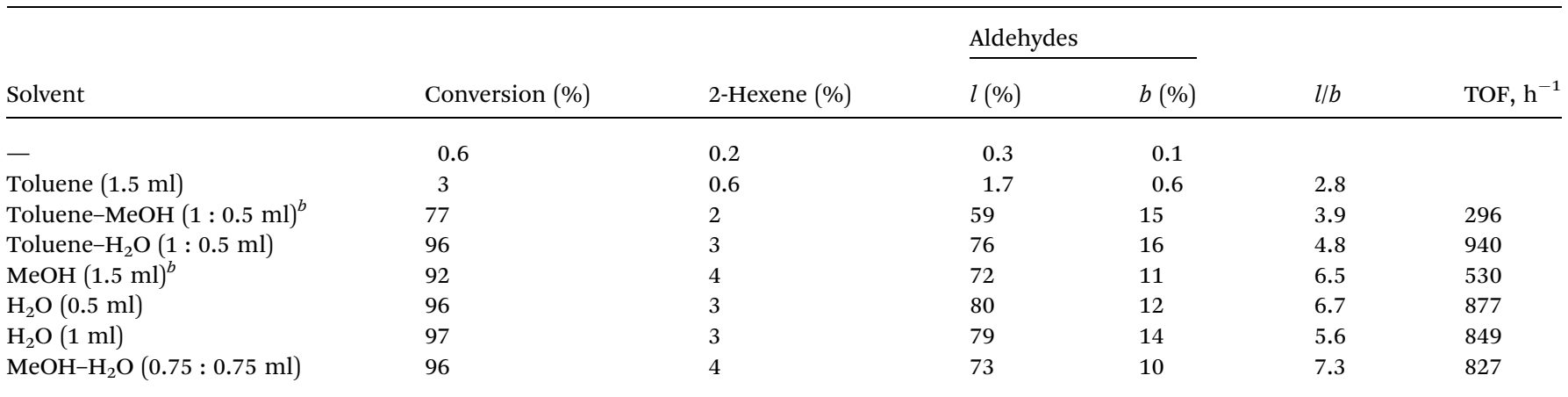

${ }^{a}$ Reaction conditions: 1 -hexene $1.5 \mathrm{ml}(0.012 \mathrm{~mol}),[1$-hexene $] /[\mathrm{Rh}]=800,\left[\mathrm{PPh}_{3}\right] /[\mathrm{Rh}]=13, T=80{ }^{\circ} \mathrm{C}, \mathrm{H}_{2}-\mathrm{CO}(1: 1)=10 \mathrm{bar}$, time $=1 \mathrm{~h}$, autoclave $50 \mathrm{ml} .{ }^{b}$ Time $=2 \mathrm{~h}$. 
Table 3 Effect of temperature and pressure on hydroformylation of 1-hexene catalyzed by Rh/PAA $+\mathrm{PPh}_{3}$ in water ${ }^{a}$

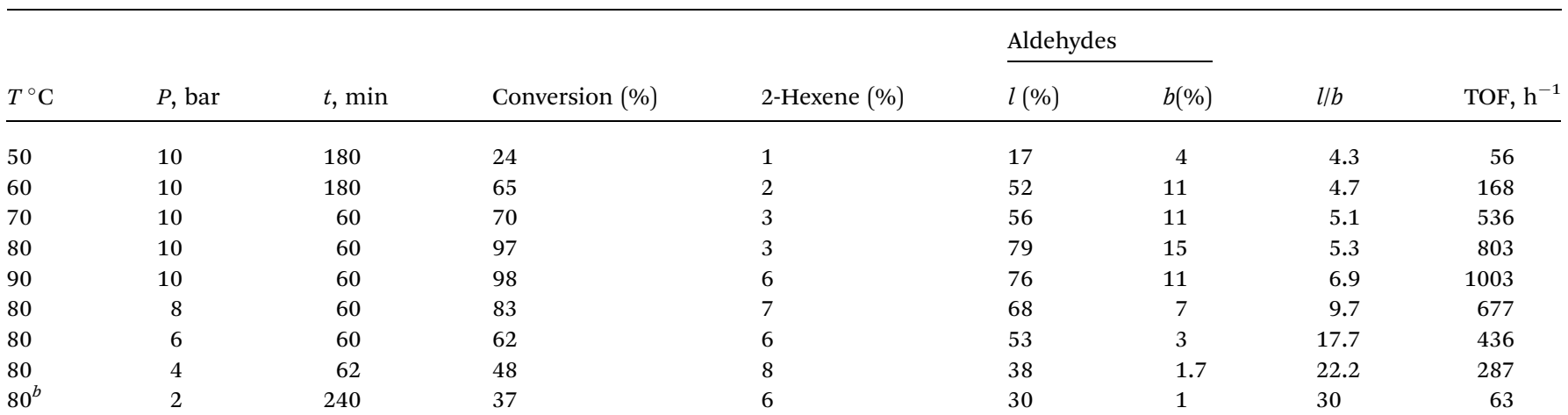

${ }^{a}$ Reaction conditions: 1 -hexene $1.5 \mathrm{ml}(0.012 \mathrm{~mol})$, water $1.5 \mathrm{ml}$, [Rh] $\left(1.5 \times 10^{-5} \mathrm{~mol}\right),[1$-hexene $] /[\mathrm{Rh}]=800,[\mathrm{PPh}] /[\mathrm{Rh}]=13$, autoclave $50 \mathrm{ml}$. ${ }^{b}$ Autoclave $100 \mathrm{ml}$, 1-hexene $3 \mathrm{ml}$, water $3 \mathrm{ml}$.
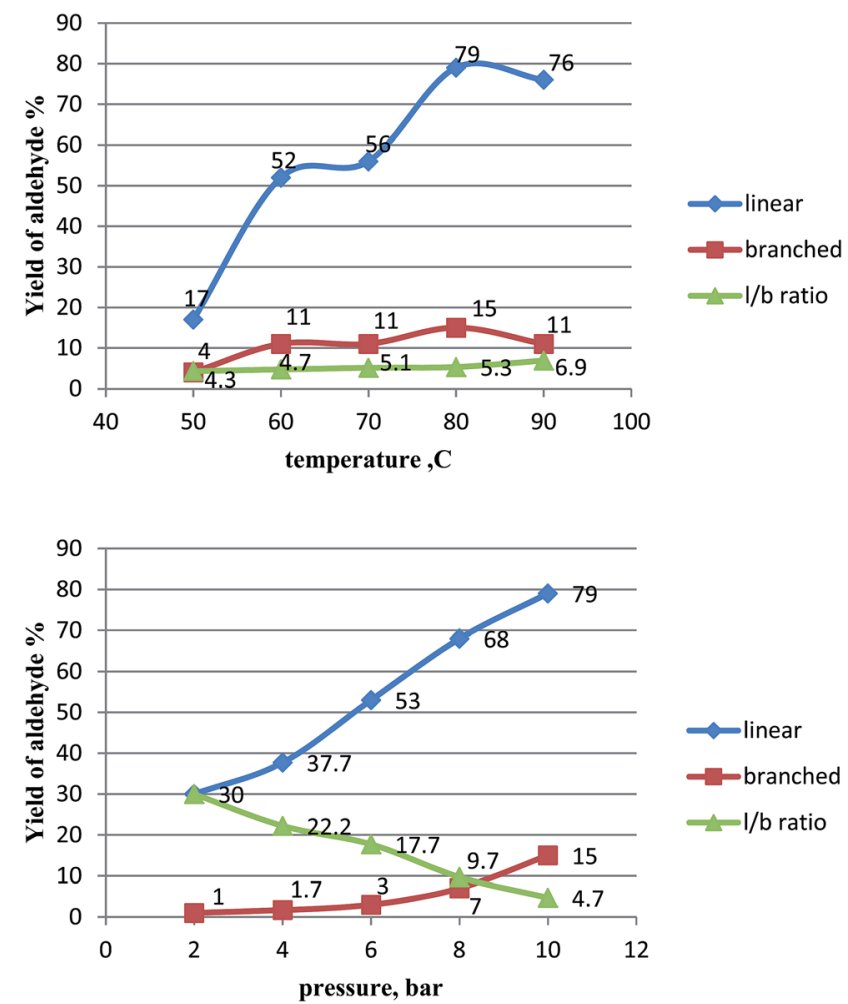

Fig. 2 Graphs depicting the influence of $1: 1 \mathrm{CO}-\mathrm{H}_{2}$ pressure and temperature on the selectivity of 1-hexene hydroformylation catalyzed by $\mathrm{Rh} / \mathrm{PAA}+\mathrm{PPh}_{3} ;\left[\mathrm{PPh}_{3}\right] /[\mathrm{Rh}]=13,[1$-hexene $] /[\mathrm{Rh}]=800$.

lower pressure, 4 or 6 bar, $l / b$ increased to attractive values, 16 and 21. Interestingly, the hydrophobic complex $\mathrm{HRh}(\mathrm{CO})\left(\mathrm{PPh}_{3}\right)_{3}$ can also be successfully applied for the hydroformylation of 1-hexene in water giving the highest TOF, $1903 \mathrm{~h}^{-1}$, noted in these studies.

Fig. 3 shows the $\mathrm{H}_{2} / \mathrm{CO}$ pressure drop during the hydroformylation of 1-hexene catalyzed by $\mathrm{Rh} / \mathrm{PAA}, \mathrm{Rh}(\mathrm{acac})(\mathrm{CO})_{2}$, and $\mathrm{HRh}(\mathrm{CO})\left(\mathrm{PPh}_{3}\right)_{3}$. As the last two systems are totally hydrophobic, the name "on water" is suitable for their description.
With these improved reaction conditions in hand, we decided to investigate the on-water hydroformylation of other alkenes. 1-Octene showed good conversion, $98 \%$ (Table 6 , entry 1 ). The on-water hydroformylation reaction using 2-hexene and styrene as the substrates gave $76 \%$ and $67.0 \%$ conversion and $76 \%$ and $64 \%$ aldehyde selectivity. However, the $l / b$ ratio was expectedly poor, 0.07 and 0.7 , respectively (Table 6).

\subsection{Recycling of the catalyst}

The reusability of Rh/PAA in the on-water hydroformylation of 1-hexene and 1-octene was studied according to two different protocols. When the reaction with 1-hexene was completed, the organic phase was separated from the aqueous phase by decantation, and the aqueous phase was placed again in an autoclave. All liquid components were removed from the organic phase by "vacuum transfer", a new portion of olefin and $\mathrm{PPh}_{3}$ were added to the residue, and the resulting mixture was introduced to the autoclave. Thus, in such recycling, practically the entire amount of rhodium was used in the next catalytic cycle. The results presented in Table 7 indicate that recycling was efficient, although the third reaction was slower than the second one. An increase in the $l / b$ ratio from 6.5 to 8.1 was noted.

In reaction with 1-octene as the substrate, only the water phase was used for the first recycling producing $70.9 \%$ of aldehydes. For the next run, all rhodium was used again, according to the procedure described for 1-hexene.

\subsection{The nature of the catalyst}

The results of recycling experiments indicated the leaching of rhodium from the water to the organic phase. To verify that conclusion, the ${ }^{31} \mathrm{P}$ NMR spectrum of the organic phase separated after hydroformylation with $\mathrm{Rh} / \mathrm{PAA}+\mathrm{PPh}_{3}$ was measured. It showed a broad doublet at $32.2 \mathrm{ppm}$ with $J_{\mathrm{Rh}-\mathrm{P}} 133.8 \mathrm{~Hz}$ confirming the presence of a rhodium species. In addition, according to the ICP analysis, $c a$. $50 \%$ of rhodium was transferred to the organic phase during the catalytic process. 
Table 4 Effect of $[\mathrm{L}] /[\mathrm{Rh}]$ ratio ( $\mathrm{L}=$ phosphine) on hydroformylation of 1-hexene with Rh/PAA in water ${ }^{d}$

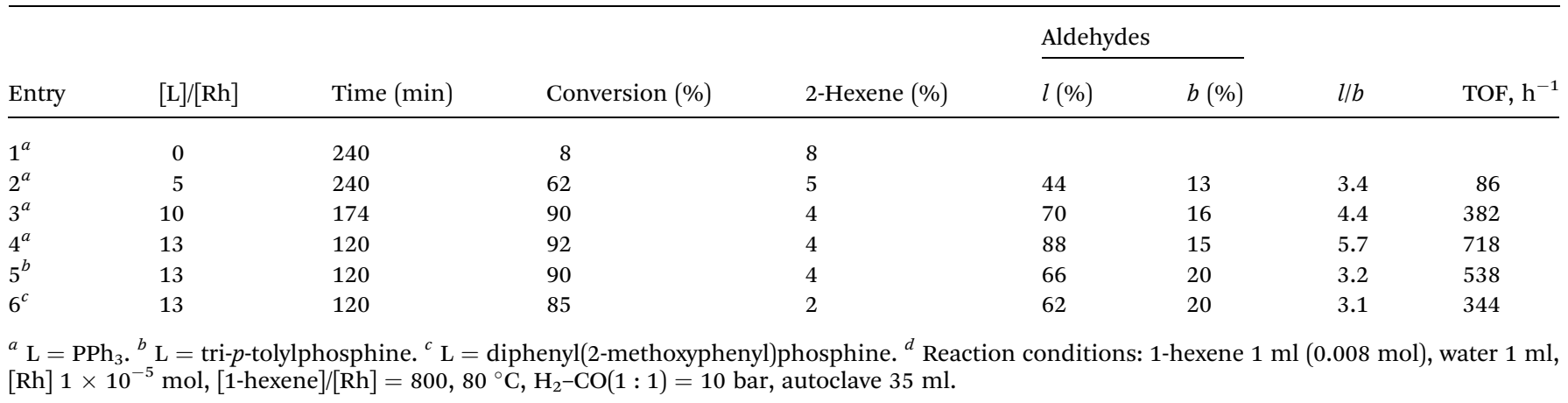

Table 5 Hydroformylation of 1-hexene catalyzed by different rhodium complexes in water ${ }^{a}$

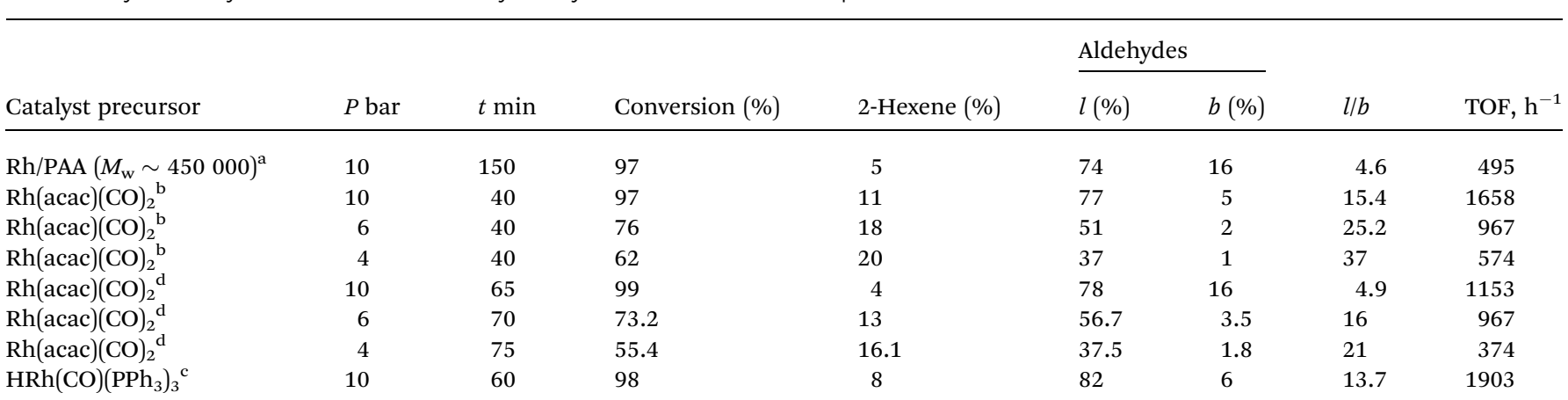

${ }^{a}$ Reaction conditions: ${ }^{\mathrm{a}, \mathrm{d}}$ 1-hexene $1 \mathrm{ml}(0.008 \mathrm{~mol})$, water $1 \mathrm{ml}$, autoclave $35 \mathrm{ml}$, b,c 1 -hexene $1.5 \mathrm{ml}(0.012 \mathrm{~mol})$, water $1.5 \mathrm{ml}$, autoclave $50 \mathrm{ml},{ }^{\mathrm{a}, \mathrm{b}, \mathrm{c}}[1$-hexene $] /[\mathrm{Rh}]=800,\left[\mathrm{PPh}_{3}\right] /[\mathrm{Rh}]=13,{ }^{\mathrm{d}}[1$-hexene $] /[\mathrm{Rh}]=420,\left[\mathrm{PPh}_{3}\right] /[\mathrm{Rh}]=6.8 . T=80^{\circ} \mathrm{C}$.

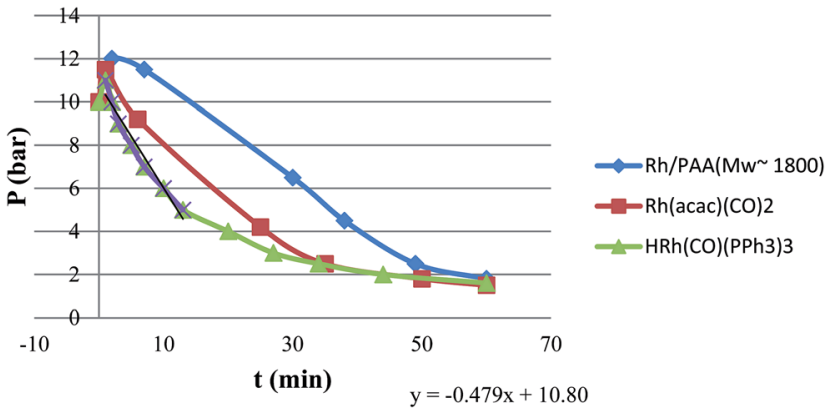

Fig. 3 Changes of $\mathrm{H}_{2} / \mathrm{CO}$ pressure vs. time during hydroformylation of 1-hexene catalyzed by $\mathrm{Rh} / \mathrm{PAA}, \mathrm{Rh}(\mathrm{acac})(\mathrm{CO})_{2}$ and $\mathrm{HRh}(\mathrm{CO})\left(\mathrm{PPh}_{3}\right)_{3}$ in the presence of $\mathrm{PPh}_{3}\left(\left[\mathrm{PPh}_{3}\right] /[\mathrm{Rh}]=13\right)$ in water. [1-Hexene]/[Rh] = $800, T=80^{\circ} \mathrm{C}, \mathrm{H}_{2}-\mathrm{CO}(1: 1)=10$ bar. Linear approximation used for determination of TOF was shown for reaction with $\mathrm{HRh}(\mathrm{CO})\left(\mathrm{PPh}_{3}\right)_{3}$.

For a better understanding of rhodium transformations in the studied system, the reaction of $\mathrm{Rh}(\mathrm{acac})(\mathrm{CO})_{2}$ with $\mathrm{PPh}_{3}$ and $\mathrm{H}_{2}$ (1 bar) was performed in water. It should be mentioned that $\mathrm{PPh}_{3}$ reacts with $\mathrm{Rh}(\mathrm{acac})(\mathrm{CO})_{2}$ in any organic solvent producing $\mathrm{Rh}$ (acac)(CO) $\left(\mathrm{PPh}_{3}\right)$, which in the presence of $\mathrm{PPh}_{3}$ excess and $\mathrm{H}_{2} / \mathrm{CO}$ forms a catalytically active hydrido-carbonyl species. Reaction with $\mathrm{H}_{2} / \mathrm{CO}$ takes place only under elevated pressure, and no reaction was observed at atmospheric pressure in benzene or toluene. In contrast, formation of $\mathrm{HRh}(\mathrm{CO})\left(\mathrm{PPh}_{3}\right)_{3}$ was observed in the presence of methanol or isopropanol. Unexpectedly, when a suspension of Rh(acac) $(\mathrm{CO})_{2}$ and $\mathrm{PPh}_{3}$ in water was treated with $\mathrm{H}_{2}$ (1 bar), the complex $\mathrm{HRh}(\mathrm{CO})\left(\mathrm{PPh}_{3}\right)_{3}$ was formed in a stoichiometric amount (Scheme 2).

Such a synthetic procedure differs remarkably from those reported in the literature. ${ }^{18-20}$ The most efficient syntheses of $\mathrm{HRh}(\mathrm{CO})\left(\mathrm{PPh}_{3}\right)_{3}$ apply $\mathrm{KOH}, \mathrm{NaBH}_{4}$, or hydrazine in an ethanol solution. ${ }^{18}$

\section{Conclusions}

It was demonstrated that the hydroformylation of 1-hexene can be very efficiently performed in water using water-soluble

Table 6 On water hydroformylation of different alkenes catalyzed by $\mathrm{Rh} / \mathrm{PAA}+\mathrm{PPh}_{3}{ }^{b}$

\begin{tabular}{|c|c|c|c|c|c|c|}
\hline \multirow[b]{2}{*}{ Substrate } & \multirow[b]{2}{*}{$t, \min$} & \multirow[b]{2}{*}{ Conv. $^{a}(\%)$} & \multicolumn{2}{|c|}{ Aldehydes } & \multirow[b]{2}{*}{$l / b$} & \multirow[b]{2}{*}{ TOF, $\mathrm{h}^{-1}$} \\
\hline & & & $l(\%)$ & $b(\%)$ & & \\
\hline 1-Octene & 120 & 98 & 77 & 13 & 5.9 & 760 \\
\hline 2-Hexene & 180 & 76 & 5 & 71 & 0.07 & 216 \\
\hline Styrene & 90 & 67 & 26 & 38 & 0.7 & 389 \\
\hline
\end{tabular}

${ }^{a} \mathrm{Rh}(\mathrm{acac})(\mathrm{CO})_{2}$ as catalyst, $[1$-hexene $] /[\mathrm{Rh}]=420,\left[\mathrm{PPh}_{3}\right] /[\mathrm{Rh}]=6.5, p=$ 1 bar. ${ }^{b}$ Reaction conditions: Substrate $1.5 \mathrm{ml}$, water $1.5 \mathrm{ml}$, [sub]/[Rh] = $800, \mathrm{~L}=\mathrm{PPh}_{3}\left[\mathrm{PPh}_{3}\right] /[\mathrm{Rh}]=13, T=80^{\circ} \mathrm{C}, \mathrm{P}\left(\mathrm{H}_{2}-\mathrm{CO}\right)=1: 1, p=10$ bar. 
Table 7 Recycling Rh/PAA catalyst in the hydroformylation of 1-hexene and 1-octene in water ${ }^{a}$

\begin{tabular}{|c|c|c|c|c|c|c|}
\hline Substrate & Time min & Conversion (\%) & 2-Hexene $(\%)$ & Aldehydes \% & $l / b$ & TOF, $\mathrm{h}^{-1}$ \\
\hline \multirow[t]{2}{*}{ 1-Hexene } & 70 & 95.7 & 4.8 & 90.9 & 6.5 & 752 \\
\hline & 120 & 95.6 & 4.1 & 90.1 & 6.7 & 751 \\
\hline \multirow[t]{3}{*}{ 1-Octene } & 120 & 97.7 & 3.7 & 92.4 & 3.8 & \\
\hline & 120 & 77 & 2.4 & 70.9 & 4.1 & \\
\hline & 120 & 95.2 & 2.2 & 91.4 & 3.9 & \\
\hline
\end{tabular}

${ }^{a}$ Reaction conditions: $[\mathrm{sub}] /[\mathrm{Rh}]=800, \mathrm{~L}$ is $\mathrm{PPh}_{3}\left[\mathrm{PPh}_{3}\right] /[\mathrm{Rh}]=13, T=80^{\circ} \mathrm{C}, p\left(\mathrm{H}_{2}-\mathrm{CO}\right)=1: 1, p=10$ bar.

$$
\mathrm{Rh}(\mathrm{acac})(\mathrm{CO})_{2}+\mathrm{PPh}_{3}+\mathrm{H}_{2} \underset{\mathrm{H}_{2} \mathrm{O}}{\longrightarrow} \mathrm{HRh}(\mathrm{CO})\left(\mathrm{PPh}_{3}\right)_{3}
$$

Scheme 2

$\mathrm{Rh} / \mathrm{PAA}$ or water insoluble $\mathrm{Rh}(\mathrm{acac})(\mathrm{CO})_{2}$ complexes with an excess of hydrophobic $\mathrm{PPh}_{3}$. Such "on water" methodology is very simple and, in particular, the application of an expensive water soluble phosphine is not needed to perform hydroformylation. Also, the organic solvent is eliminated from the system. Moreover, aldehydes were formed as the main products under relatively mild conditions, $80^{\circ} \mathrm{C}$ and 10 bar. At a lower pressure, a linear aldehyde can be obtained with excellent selectivity.

The presented systems can be used for any higher olefin, as was demonstrated for 1-hexene, 2-hexene, and 1-octene.

Recycling experiments showed that a rhodium catalyst can be recovered without a loss of its catalytic activity. However, during hydroformylation rhodium is leached to the organic phase, which complicates the efficient separation of aldehydes from the catalyst. We are now working on the improvement of this step and preliminary results show that after the catalytic cycle rhodium can be transferred back to the water phase.

Explanation of the high catalytic activity of the presented "on water" system can only in part be based on specific interactions between the reactants, similarly as it was described in the literature. In our opinion, reactions of the rhodium precursor with $\mathrm{H}_{2} / \mathrm{CO}$ are remarkably influenced by the presence of water, which is not only a solvent but also a reactant. As was shown, in a water medium, a catalytically active $\mathrm{HRh}(\mathrm{CO})\left(\mathrm{PPh}_{3}\right)_{3}$ complex was formed in high yield under very mild conditions as a result of efficient $\mathrm{H}_{2}$ activation. Such activation was realized without any additives, in particular in the absence of a base that could eventually facilitate heterolytic splitting of $\mathrm{H}_{2}$.

In conclusion it should be pointed out that in the presented catalytic systems water plays not only the role of a reaction medium but it is also involved in the chemical transformations of rhodium complexes to catalytically active forms. A combination of these two functions results in the creation of a very active, simple, and environmentally friendly catalytic system for the hydroformylation of higher olefins.

\section{Acknowledgements}

Authors thank Prof. Yuri Varshavsky for important contribution in the synthesis of Rh/PAA and prof. David Cole-Hamilton for very inspiring discussions.

\section{References}

1 (a) Applied Homogenous Catalysis with Organometallic Compounds: A Comprehensive Handbook in Two Volumes, ed. B. Cornils and W. A. Herrmann, VCH Weinheim, 1996; (b) Rhodium Catalysed Hydroformylation, ed. P. W. N. M. van Leeuwen and C. Claver, Kluwer Academic Publisher, Dordrecht, 2000; (c) W. G. Parshall and S. D. Ittel, Homogenous Catalysis: The Application and Chemistry of Catalysis by Soluble Transition Metal Complexes, John Wiley \& Sons, Inc., New York, 1992; (d) Metal Catalysis in Industrial Organic Processes, ed. G. P. Chiusoli and P. M. Maitlis, PSC Publishing, 2006; (e) S. Bhaduri and D. Mukesh, Homogeneous Catalysis. Mechanisms and Industrial Application, Wiley-Interscience, 2000; (f) Transition Metals for Organic Synthesis. Building Blocks and Fine Chemicals, ed. M. Beller and C. Bolm, Wiley-VCH Verlag GmbH \& Co. KGaA, 2004; $(g)$ M. Beller, B. Cornils, C. D. Frohning and C. W. Kohlpaintner, J. Mol. Catal. A: Chem., 1995, 104, 17; (h) A. M. Trzeciak and J. J. Ziółkowski, Coord. Chem. Rev., 1999, 190-192, 883; (i) A. M. Trzeciak, Hydroformylation in: Comprehensive Inorganic Chemistry II: from elements to applications, ed. J. Reedijk and K. Poeppelmeier, Elsevier, Amsterdam, 2013, vol. 6, p. 25; (j) B. Breit and W. Seiche, Synthesis, 2001, 1; (k) A. Behr and P. Neubert, Applied Homogeneous Catalysis, Wiley-VCH, Weinheim, 2012.

2 R. N. Butler and A. G. Coyne, Chem. Rev., 2010, 110, 6302.

3 N. Shapiro and A. Vigalok, Angew. Chem., 2008, 120, 2891.

4 S. Mellouli, L. Bousekkine, A. B. Theberge and W. T. S. Huck, Angew. Chem., Int. Ed., 2012, 51, 7981.

5 S. K. Rout, S. Guin, J. Nath and B. K. Patel, Green Chem., 2012, 14, 2491.

6 P. Norcott, C. Spielman and C. S. P. McErlean, Green Chem., 2012, 14, 605.

7 Y. Jung and R. A. Marcus, J. Am. Chem. Soc., 2007, 129(17), 5492. 8 J. S. Yadav, T. Swamy, B. V. S. Reddy and D. K. Rao, J. Mol. Catal. A: Chem., 2007, 274, 116. 
9 S. Narayan, J. Muldoon, M. G. Finn, V. V. Fokin, H. C. Kolb and K. B. Sharpless, Angew. Chem., Int. Ed., 2005, 44, 3275.

10 F. Joó, P. Csiba and A. Bényei, J. Chem. Soc., Chem. Commun., 1993, 1602.

11 A. Breslow, W. Maitra and D. Rideout, Tetrahedron Lett., 1983, 24, 1901.

12 A. Meijer, S. Otto and J. B. F. N. Engberts, J. Org. Chem., 1998, 63, 8989.

13 O. Diebolt, C. Müller and D. Vogt, Catal. Sci. Technol., 2012, $2,773$.

14 S. L. Desset, S. W. Reader and D. J. Cole-Hamilton, Green Chem., 2009, 11, 630.

15 H. Nowothnick, A. Rost, T. Hameria, R. Schomäker, C. Müller and D. Vogt, Catal. Sci. Technol., 2013, 3, 600.
16 Y. S. Varshavsky and T. G. Cherkasova, Zh. Neorg. Khim., 1967, 12, 1709.

17 The first synthesis of Rh/PAA was presented by Y. S. Varshvskii and T. G. Tcherkasova, on Ruscatal Conference, Abstracts, vol. 2, p. 123.

18 D. Evans, G. Yagupsky and G. Wilkinson, J. Chem. Soc. A, 1968, 2660.

19 (a) Y. S. Varshavsky, T. G. Cherkasova and I. S. Podkorytov, Inorg. Chem. Commun., 2004, 7, 489; (b) Y. S. Varshavsky, T. G. Cherkasova, L. S. Podkorytov, A. A. Korlyukov, V. N. Khrustalev and A. B. Nikolskii, Russ. J. Coord. Chem., 2005, 31(2), 121.

20 A. M. Trzeciak and J. J. Ziółkowski, J. Organomet. Chem., 1992, 429, 239. 